\title{
Preliminary study of anesthetic risk factors in surgery for pathologic fractures secondary to metastatic tumors
}

Received July 3, 2017

Revised 1st, September 13, 2017

2nd, October 2, 2017

Accepted October 13, 2017

\section{Corresponding author}

Jun Rho Yoon, M.D., Ph.D.

Department of Anesthesiology and Pain Medicine, Bucheon St. Mary's Hospital, College of Medicine, The Catholic University of Korea, 327 Sosa-ro, Wonmi-gu, Bucheon 14647, Korea

Tel: 82-32-340-7075

Fax: 82-32-340-2255

E-mail: pauly@catholic.ac.kr

\section{ORCID}

http://orcid.org/0000-0001-7457-7433

\section{Tae Kwane Kim, Jun Rho Yoon, Youngmyung Noh, Hye Jin Yoon, Mi Sun Park, and Young-hye Kim}

Department of Anesthesiology and Pain Medicine, Bucheon St. Mary's Hospital, College of Medicine, The Catholic University of Korea, Seoul, Korea
Background: Despite advances in the treatment of primary cancer, metastatic pathologic fractures still affect the survival of cancer patients. The goals of surgery, such as those with terminal cancer, are to maintain a maximum level of independence and improve the quality of life. A patient may be a poor surgical candidate because of a short life expectancy or illness that is too severe to benefit from surgical fixation. Moreover, this surgery is an operation accompanied with significant morbidity and mortality. This retrospective study investigated the characteristics of these patients and assessed the influence of anesthetic risk factors on the outcome.

Methods: The records of 45 patients with pathologic fractures who underwent surgical stabilization for metastatic factors from 1 January 1995 to 31 December 2013 at our hospital were reviewed. Demographic data, various severity scores, anesthetic factors, and survival were reviewed.

Results: The most common sites of primary tumors were lung, liver and stomach. The predominant sites of pathologic fractures were the femur (71.1\%); six lesions were in the humerus and four in the spine. Univariate and multivariate analyses identified several prognostic factors with a significantly worse influence on survival, including lung tumor and Acute Physiology and Chronic Health Evaluation (APACHE) II score.

Conclusions: Although the number of patients was too small to result in a satisfactory appraisal, the most important step is to select candidates to gain the benefits of palliative surgery. We suggest the possibility of APACHE II scoring and the recognition of lung cancer in making the clinical decision of performing the palliative osteosyntheses for patients with pathologic fractures.

Key Words: Anesthesia, Cancer, Pathologic fracture, Survival.

\section{INTRODUCTION}

The skeleton is the third most common site of metastatic cancer. One-third to half of all cancers metastasize to the skeleton $[1,2]$. Metastatic tumor cells that colonize the bone matrix tend to cause bone resorption at the sites of tumor cell deposits and increase the probability of the occurrence of fractures [3]. The onset of pathologic fracture signals decreases the life span for patients with bone metastases in multiple tumor types [4,5]. Advances in therapeutic technology for cancer have prolonged patient survival, which ironically has increased the incidence of pathologic fractures [4].

This is an Open Access article distributed under the terms of the Creative Commons Attribution Non-Commercial License (http://creativecommons.org/licenses/by-nc/4.0) which permits unrestricted non-commercial use, distribution, and reproduction in any medium, provided the original work is properly cited. 
Since tumor metastases reflect an advanced stage of disease, patients with fractures through metastatic lesions are often considered unsuitable for surgery [6]. However, the outstandingly longer patient survival that has been achieved makes conservative care no longer an acceptable option because the patients are frequently bedridden, capable of only a few simple social interactions, and in agony [6].

The goal of palliative therapy is to lengthen the life span and relieve symptoms for the duration of the patient's life without causing other symptoms [7]. Palliative surgery differs from other kinds of surgery in that most of candidates are near the end of their lives and tend to become more physiologically compromised over time [8]. These surgeries tend to be performed aggressively $[5,6]$. The operation itself may shorten a patient's life because of exacerbation of the primary tumor, postoperative complications, and the spread of metastases. Furthermore, the anesthetic risk in palliative surgery is considered higher than usual and anesthetic procedures should be carefully applied $[8,9]$.

The aim of this retrospective study was to investigate the medical conditions of patients for palliative surgery and elucidate anesthesia-related factors on outcome along with a literature review.

\section{MATERIALS AND METHODS}

Data were retrospectively collected by reviewing all the charts of patients with known metastatic pathologic fractures from 1 January 1995 to 31 December 2013. We identified all patients who underwent operations for pathologic fractures secondary to metastatic tumors during this period in our operating suites. All the medical charts were reviewed until a minimum of two years or death after surgeries. The diagnosis was intra- or postoperatively confirmed in all patients by histopathologic examination. We collected data on age, gender, body mass index, origin of primary tumor, fracture site, visceral metastasis, therapeutic history, surgical time, blood transfusion, net fluid balance, number of postoperative days in the intensive care unit (ICU), complications, and days to death.

We used a variety of severity scores, including the classification of the American Society of Anesthesiologists, Eastern Cooperative Oncology Group performance status (ECOG), Acute Physiology and Chronic Health Evaluation (APACHE)
II, Logistic Organ Dysfunction score (LODS), and Charlson score to explore their correlation to the operation-related risk.

The result of surgery was graded as an unsuitable outcome if any of the following three criteria were met: presence of significant complications within 30 days postoperatively which possibly result in serious morbidity, postoperative ICU admission exceeding 2 days, and death from operation for fracture less than 6 months postoperatively. Accordingly, patients were divided into the suitable and unsuitable group. Odds ratio (OR) comparisons included lung, liver, and stomach tumors with the other tumors, femur fractures with other fracture sites, and general, combined general and regional, and regional anesthesia. The cases were analyzed with respect to use of transfusion, intraoperative blood loss volume, operative time, and complications between both groups.

Survival in days was calculated from the day of operation to death. The day of death was determined from medical charts and phone interviews until 31 December 2015. Clinical characteristics were recorded as number (percentage) for categorical variables, and mean \pm standard deviation for continuous variables.

Differences between the suitable and unsuitable groups were compared using the Wilcoxon rank sum test for continuous variables and the chi-square or Fisher exact test for categorical variables. Univariable and multivariable logistic regression analyses were performed to identify independent predictors of patients not suitable for surgery. Time to event (180-day death) analysis was performed using Cox proportional hazard regression and reported as hazard ratios (HRs) with 95\% confidence intervals (CIs) and as Kaplan-Meier curves with a corresponding log-rank test. We checked proportional hazards assumptions with a test based on Schoenfeld residuals. We selected variables for the adjusted multivariable analysis if their $P$ value was $<0.050$ in the univariable analysis. All statistical significance was determined by $\mathrm{P}<$ 0.050. All statistical analyses were performed using SAS 9.3 (SAS institute Inc., USA).

\section{RESULTS}

Forty five patients comprised 18 men and 27 women and age range was from 40 to 96 years. The age distribution was the 8 th decade $(n=14)$, 7 th decade $(n=11)$, 9th decade $(n=$ $10)$, 6th decade $(n=6), 5$ th decade $(n=3)$, and 10th decade ( $n$ 
$=1$ ). The mean body mass index is 21.3. Lung, liver and stomach carcinomas accounted for most of the primary lesions (Table 1). Primary cancer diagnosis was lung $(n=13)$, liver ( $n$ $=6)$, and stomach $(n=4)$. Fractures were most often located in the femur $(\mathrm{n}=32)$ followed by the humerus $(\mathrm{n}=6)$ and radius $(n=4)$ (Table 1). All fractures were treated with an internal fixation device or prosthetic implant. Twenty-two patients

Table 1. Distribution of Factors

\begin{tabular}{|c|c|}
\hline Variable & Number \\
\hline \multicolumn{2}{|l|}{ Primary cancer diagnosis } \\
\hline Lung & 13 \\
\hline Liver & 6 \\
\hline Stomach & 4 \\
\hline MUO* & 3 \\
\hline Thyroid & 2 \\
\hline Breast & 2 \\
\hline Prostate & 2 \\
\hline Cervix & 2 \\
\hline Esophagus & 2 \\
\hline Colon & 2 \\
\hline Hematopoiesis & 2 \\
\hline Others $^{\dagger}$ & 5 \\
\hline \multicolumn{2}{|l|}{ Sites of pathologic fractures } \\
\hline Femur & 32 \\
\hline Humerus & 6 \\
\hline Radius & 4 \\
\hline Spine & 2 \\
\hline Ilium & 1 \\
\hline \multicolumn{2}{|l|}{ Site of additional metastases to viscera } \\
\hline Spine & 8 \\
\hline Rib & 4 \\
\hline Humerus & 2 \\
\hline Other bones ${ }^{\ddagger}$ & 3 \\
\hline Brain & 3 \\
\hline Adrenal gland & 3 \\
\hline Liver & 2 \\
\hline Pancreas & 2 \\
\hline Peritoneum & 2 \\
\hline Pleura & 2 \\
\hline Other viscera ${ }^{\S}$ & 5 \\
\hline \multicolumn{2}{|l|}{ Therapy } \\
\hline Previous operation on for primary cancer & 12 \\
\hline Previous operation on for other cancer & 2 \\
\hline Chemotherapy & 11 \\
\hline Irradiation & 7 \\
\hline Others $^{q}$ & 5 \\
\hline
\end{tabular}

* MUO: skeletal metastasis of unknown origin. ${ }^{\dagger}$ Other primary cancer diagnosis includes pancreas, kidney, bladder, ovary, and larynx (all $n$ =1). ${ }^{\ddagger}$ Other bones include skull, radius and pelvis (all $n=1$ ). ${ }^{\S}$ Other viscera include lung, kidney, pharynx, ovary, and colon. "Other therapy includes bisphosphonates $(n=3)$ and alternative medicines and herbs $(n=2)$. had 36 additional metastases in other organs, most often the spine $(n=8)$ followed by rib $(n=4)$, brain $(n=3)$, and adrenal gland $(n=3)$ (Table 1$)$. Before the time of fracture, 12 patients had received a surgical procedure to treat the primary tumor; 11 patients had received chemotherapy and 7 patients had received irradiation (Table 1 ).

The distribution of American Society of Anesthesiologists physical status classification is $1(n=2), 2(n=13), 3(n=23)$, and $4(\mathrm{n}=7)$. The distribution of ECOG performance status scale is $0(\mathrm{n}=10), 1(\mathrm{n}=15), 2(\mathrm{n}=11), 3(\mathrm{n}=5)$, and $4(\mathrm{n}=$ 4). The mean APACHE II score is 10.5, LODS score 3.42, and Charlson co-morbidity index score 8.9. At review, 30 patients (66.7\%) had expired within 2 years postoperatively. Average postoperative survival was 621 days until 31 December 2015. Of the deaths, seven men and seven women had died by 6 months postoperatively. The mean survival time was 355 days for men and 798 days for women. This difference failed to reach statistical significance $(P>0.050)$. Twenty-eight patients $(62.2 \%)$ underwent exclusively general anesthesia. Six patients underwent regional anesthesia in addition to general anesthesia. Eleven patients received regional anesthesia only. The mean operating time was 97.3 minutes. Seventeen (37.8\%) patients received blood transfusion during surgery. The average net fluid balance for 12 patients in each group exceeded $200 \mathrm{ml}$.

Twenty patients were admitted to the ICU postoperatively. The mean length of admission was 3.1 days (range, 2-20 days). Two of these patients received mechanical ventilation. Sixteen patients (35.6\%) developed postoperative complications including wound infection, bronchopneumonia, pulmonary thromboembolism, pressure sores, and nonunion (Table 2).

Table 2. Postoperative Complication

\begin{tabular}{lc}
\hline \multicolumn{1}{c}{ Variable } & Case \\
\hline Pneumonia & 4 \\
Delirium & 3 \\
Acute renal failure & 2 \\
Coagulopathy & 1 \\
Pulmonary thromboembolism & 1 \\
Pulmonary edema & 1 \\
Pleural effusion & 1 \\
Sore & 1 \\
Wound infection & 1 \\
Nonunion with fixation failure & 1 \\
\hline
\end{tabular}


Death within 180 days occurred in 13 patients, admission to ICU beyond 2 days in nine patients, and significant complications in 16 patients. Twenty-two patients collectively were in the unsuitable group. The mean age of the suitable and unsuitable group was 67.1 and 72.3 years, respectively, with no statistical significance.

Table 3 shows the crude and adjusted odds ratios for comparing between suitable and unsuitable groups. Lung tumor was most prevalent and so was chosen as the primary tumor for purposes of comparison. In terms of lung cancer, 2 patients were in the suitable group and 11 in the unsuitable group in 180 days. The proportion of lung cancer differed significantly between the suitable group and unsuitable group $(\mathrm{P}<0.050)$. Lung carcinoma presented a significant OR $(\mathrm{P}$

Table 3. Association between Patients who are Suitable and Unsuitable for Surgery and Clinicopathological Factors

\begin{tabular}{|c|c|c|c|}
\hline Variable & Suitable $(n=23)$ & Unsuitable* $(n=22)$ & $P$ value \\
\hline Gender, female & $14(51.9)$ & $13(48.2)$ & $0.903^{\dagger}$ \\
\hline Age (yr) & $67.1(13.5)$ & $72.3(11.5)$ & $0.242^{\S}$ \\
\hline $\mathrm{BMI}\left(\mathrm{kg} / \mathrm{m}^{2}\right)$ & $21.5(3.5)$ & $21.2(4.5)$ & $0.474^{\S}$ \\
\hline \multicolumn{4}{|l|}{ Tumor } \\
\hline Others cancer & $21(65.6)$ & $11(34.4)$ & \multirow[t]{2}{*}{$0.002^{\dagger}$} \\
\hline Lung cancer & $2(15.4)$ & $11(84.6)$ & \\
\hline Additional metastasis & $11(50.0)$ & $11(50.0)$ & $0.884^{\dagger}$ \\
\hline \multicolumn{4}{|l|}{ Fracture site } \\
\hline Other bones & $8(61.5)$ & $5(38.5)$ & \multirow[t]{2}{*}{0.372} \\
\hline Femur & 15 (46.9) & $17(53.1)$ & \\
\hline History of cancer operation & $5(41.7)$ & $7(58.3)$ & $0.445^{\dagger}$ \\
\hline Chemotherapy & $5(45.5)$ & $6(54.5)$ & $0.666^{\dagger}$ \\
\hline Irradiation & $3(42.9)$ & $4(57.1)$ & $0.700^{\ddagger}$ \\
\hline \multicolumn{4}{|l|}{ ECOG scale } \\
\hline 0 & $6(60.0)$ & $4(40.0)$ & \multirow[t]{5}{*}{$0.266^{\ddagger}$} \\
\hline 1 & $10(66.7)$ & $5(33.3)$ & \\
\hline 2 & $3(27.3)$ & $8(72.7)$ & \\
\hline 3 & $3(60.0)$ & $2(40.0)$ & \\
\hline 4 & $1(25.0)$ & $3(75.0)$ & \\
\hline \multicolumn{4}{|l|}{ ASA PS classification } \\
\hline 1 & $1(50.0)$ & $1(50.0)$ & \multirow[t]{4}{*}{$0.037^{\ddagger}$} \\
\hline 2 & $10(76.9)$ & $3(23.1)$ & \\
\hline 3 & $11(47.8)$ & $12(52.2)$ & \\
\hline 4 & $1(14.3)$ & $6(85.7)$ & \\
\hline APACHE II score & $8.4(4.5)$ & $12.8(4.7)$ & $0.003^{\S}$ \\
\hline LODS score & $3.1(1.1)$ & $3.73(2.0)$ & $0.403^{\S}$ \\
\hline Charlson score & $8.8(1.0)$ & $9.1(1.2)$ & $0.712^{\S}$ \\
\hline \multicolumn{4}{|l|}{ Anesthesia } \\
\hline RA & $3(27.3)$ & $8(72.7)$ & \multirow[t]{3}{*}{$0.148^{\ddagger}$} \\
\hline $\mathrm{GA}$ & $17(60.7)$ & $11(39.3)$ & \\
\hline GARA & $3(50.0)$ & $3(50.0)$ & \\
\hline Operating time (min) & $94.4(49.8)$ & $100.4(43.6)$ & $0.322^{\S}$ \\
\hline \multicolumn{4}{|c|}{ The presence of blood transfusion } \\
\hline No & $15(53.6)$ & $13(46.4)$ & \multirow[t]{2}{*}{$0.672^{\dagger}$} \\
\hline Yes & $8(47.1)$ & $9(52.9)$ & \\
\hline \multicolumn{4}{|l|}{ Net fluid balance per hour } \\
\hline$\leq 200 \mathrm{ml}$ & $11(52.4)$ & $10(47.6)$ & \multirow[t]{2}{*}{$0.873^{\dagger}$} \\
\hline$>200 \mathrm{ml}$ & $12(50.0)$ & $12(50.0)$ & \\
\hline
\end{tabular}

Values are presented as mean (SD) or number (\%) for categorical variables. BMI: body mass index, ECOG: Eastern Cooperative Oncology Group performance status, ASA PS: American Society of Anesthesiologists physical status, APACHE: Acute Physiology and Chronic Health Evaluation, LODS: Logistic Organ Dysfunction score, RA: regional anesthesia, GA: general anesthesia, GARA: combined general and regional anesthesia. *The definition of unsuitable group includes postop significant complication or $\geq$ postop intensive care unit 2 day or death within 180 days. $P$ values of the difference between suitable and unsuitable of surgery are analyzed by ${ }^{\dagger}$ chi-square, ${ }^{\ddagger}$ Fisher's exact test and ${ }^{\S}$ Wilcoxon rank sum test. 
$<0.050$ ) (Table 4). Among 32 patients with femur fractures, 15 were in the suitable group and 17 in the unsuitable group (Table 3). The number of additional organ metastases do not have influence on the survival (Fig. 1), Presence of femur fracture did not have a significant OR $(\mathrm{P}>0.050)$ (Table 4). Among previous therapy and the scores studied, only the APACHE II score had a statistically significant OR. The APACHE II score was statistically lower in the suitable group compared with the unsuitable group $(\mathrm{P}<0.050)$ (Table 4$)$.

Univariate logistic regression analysis identified lung cancer $(\mathrm{OR}=10.50, \mathrm{P}=0.006)$ and higher APACHE II $(\mathrm{OR}=1.24$, $\mathrm{P}=0.007$ ) as factors associated with unsuitable group (Table 4). The type of anesthesia, operating time, the need for blood transfusion and net fluid balance did not significantly affect either patient group in terms of OR (Table 4). Multivariable logistic regression analysis after adjustment, lung cancer (OR

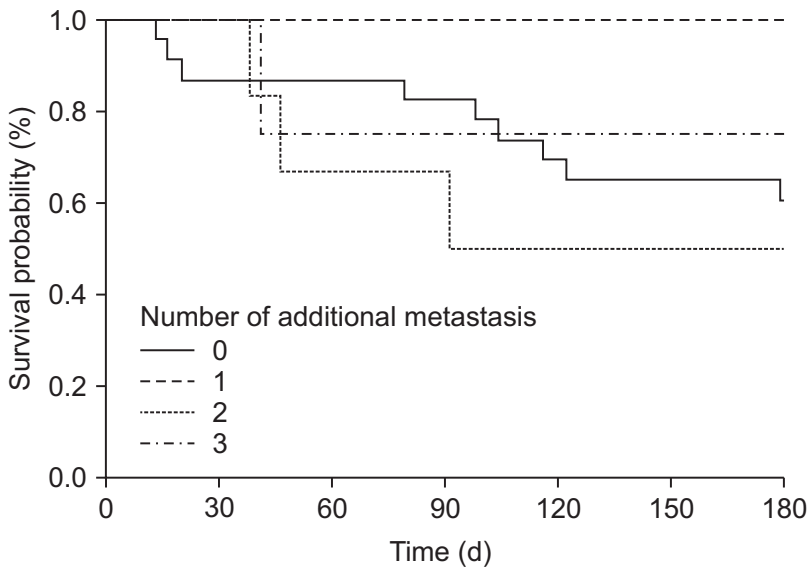

Fig. 1. Kaplan-Meier survival curves according to the number of additional organ metastasis.

Table 4. Univariable and Multivariable Logistic Regression of Unsuitable Group for Surgery

\begin{tabular}{|c|c|c|c|c|}
\hline Variable & Crude OR (95\% Cl) & P value & Adjust OR (95\% Cl) & $P$ value \\
\hline Gender, female & $0.93(0.28-3.06)$ & 0.903 & & \\
\hline Age (yr) & $1.04(0.99-1.09)$ & 0.903 & & \\
\hline BMI $\left(\mathrm{kg} / \mathrm{m}^{2}\right)$ & $0.98(0.85-1.14)$ & 0.792 & & \\
\hline Tumor, lung cancer & $10.50(1.97-55.97)$ & 0.006 & $8.39(1.38-50.90)$ & 0.021 \\
\hline Additional metastasis & $1.09(0.34-3.51)$ & 0.884 & & \\
\hline Fracture site, femur & $1.81(0.49-6.76)$ & 0.375 & & \\
\hline History of cancer operation & $1.68(0.44-6.39)$ & 0.447 & & \\
\hline Chemotherapy & $1.35(0.35-5.28)$ & 0.666 & & \\
\hline Irradiation & $1.48(0.29-7.54)$ & 0.636 & & \\
\hline \multicolumn{5}{|l|}{ ECOG scale (reference $=0$ ) } \\
\hline 1 & $0.75(0.14-3.94)$ & 0.734 & & \\
\hline 2 & $4.00(0.64-25.02)$ & 0.138 & & \\
\hline 3 & $1.00(0.11-8.95)$ & $>0.999$ & & \\
\hline 4 & $4.50(0.34-60.15)$ & 0.256 & & \\
\hline \multicolumn{5}{|l|}{ ASA PS classification (reference $=1$ ) } \\
\hline 2 & $0.30(0.01-6.38)$ & 0.440 & & \\
\hline 3 & $1.09(0.06-19.63)$ & 0.953 & & \\
\hline 4 & $6.00(0.18-196.12)$ & 0.314 & & \\
\hline APACHE II score & $1.24(1.06-1.45)$ & 0.007 & $1.22(1.03-1.44)$ & 0.024 \\
\hline LODS score & $1.29(0.87-1.92)$ & 0.207 & & \\
\hline Charlson index & $1.26(0.72-2.22)$ & 0.415 & & \\
\hline \multicolumn{5}{|l|}{ Anesthesia } \\
\hline GA & $2.16(0.52-8.90)$ & 0.287 & & \\
\hline GARA & Reference & & & \\
\hline RA & $1.80(0.30-10.64)$ & 0.517 & & \\
\hline Operating time & $1.00(0.99-1.02)$ & 0.666 & & \\
\hline The presence of blood transfusion & $1.30(0.39-4.34)$ & 0.672 & & \\
\hline Net fluid balance per hour $>200 \mathrm{ml}$ & $1.10(0.34-3.55)$ & 0.873 & & \\
\hline
\end{tabular}

The analysis predicts unsuitable group compared to suitable group. OR: odds ratio, Cl: confidence interval, BMl: body mass index, ECOG: Eastern Cooperative Oncology Group performance status, ASA PS: American Society of Anesthesiologists physical status, APACHE: Acute Physiology and Chronic Health Evaluation, LODS: Logistic Organ Dysfunction score, GA: general anesthesia, GARA: combined general and regional anesthesia, RA: regional anesthesia. 
$=8.39, \mathrm{P}=0.021)$ and APACHE II $(\mathrm{OR}=1.22, \mathrm{P}=0.024)$ also remained statistically significant.

In terms of the analysis in comparing between survivors and non-survivors, the median follow-up duration of the survivors was 310 days. Univariable analysis demonstrated significant independent risk factors for 180-day mortality, which included lung cancer ( $\mathrm{HR}=5.26,95 \% \mathrm{CI}$ : 1.71-16.20, $\mathrm{P}=0.004)$ and higher APACHE II score $(\mathrm{HR}=1.14,95 \% \mathrm{CI}$ : 1.02-1.26, $\mathrm{P}=0.022$ per 1 point increase) (Table 5). KaplanMeier survival curve shows a significant difference comparing lung cancer to others by log rank test $(\mathrm{P}<0.001)$ (Fig. 2). Finally, the only statistically significant factor after multivariable analysis was the lung cancer increasing the risk of death (HR $=4.17,95 \%$ CI: 1.16-15.05, $\mathrm{P}=0.029)$ (Table 5).

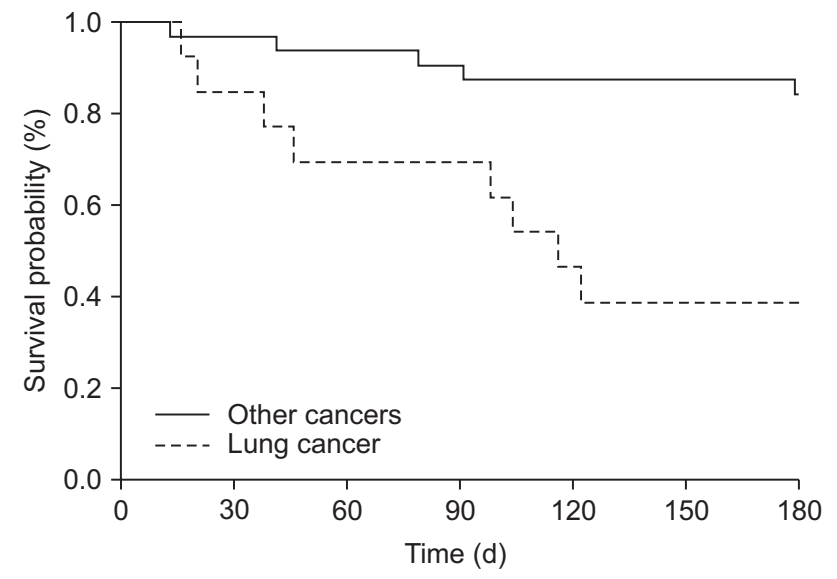

Fig. 2. Kaplan-Meier survival curves comparing between lung cancer and other cancers.

Table 5. Univariable and Multivariable Cox Proportional-Hazards Regression for 180 Days Overall Survival

\begin{tabular}{|c|c|c|c|c|c|c|}
\hline Variable & $\begin{array}{l}\text { Survival } \\
(n=32)\end{array}$ & $\begin{array}{l}\text { Death } \\
(n=13)\end{array}$ & $\begin{array}{l}\text { Crude HR } \\
(95 \% \mathrm{Cl})\end{array}$ & $P$ value & $\begin{array}{c}\text { Adjusted HR } \\
(95 \% \mathrm{Cl})\end{array}$ & $P$ value \\
\hline Gender, female & $21(77.80)$ & $6(22.20)$ & $2.13(0.72-6.36)$ & 0.174 & & \\
\hline Age (yr) & $68.56(12.87)$ & $72.31(12.18)$ & $1.03(0.98-1.08)$ & 0.302 & & \\
\hline $\mathrm{BMI}\left(\mathrm{kg} / \mathrm{m}^{2}\right)$ & $21.69(4.19)$ & $20.40(3.46)$ & 0.94 (0.81-1.09) & 0.392 & & \\
\hline Tumor, lung cancer & $5(15.63)$ & $8(61.54)$ & $5.26(1.71-16.20)$ & 0.004 & 4.17 (1.16-15.05) & 0.029 \\
\hline Additional metastasis & $18(56.25)$ & $4(30.77)$ & $0.43(0.13-1.40)$ & 0.161 & & \\
\hline Fracture site, femur & $22(68.75)$ & $10(76.92)$ & $1.45(0.40-5.26)$ & 0.575 & & \\
\hline History of cancer operation & $8(25.00)$ & $4(30.77)$ & $1.32(0.41-4.29)$ & 0.643 & & \\
\hline Chemotherapy & $8(25.00)$ & $3(23.08)$ & $0.98(0.27-3.55)$ & 0.972 & & \\
\hline Irradiation & $5(15.63)$ & $2(15.38)$ & $1.04(0.23-4.68)$ & 0.963 & & \\
\hline \multicolumn{7}{|l|}{ ECOG scale } \\
\hline 0 & $8(25.00)$ & $2(15.38)$ & & & & \\
\hline 1 & $10(31.25)$ & $5(38.46)$ & $1.74(0.34-8.98)$ & 0.507 & & \\
\hline 2 & $9(28.13)$ & $2(15.38)$ & $0.90(0.13-6.37)$ & 0.913 & & \\
\hline 3 & $3(9.38)$ & $2(15.38)$ & $2.21(0.31-15.68)$ & 0.429 & & \\
\hline 4 & $2(6.25)$ & $2(15.38)$ & $3.43(0.48-24.43)$ & 0.218 & & \\
\hline \multicolumn{7}{|l|}{ ASA PS classification } \\
\hline 1 & $2(6.25)$ & $0(0.00)$ & - & - & & \\
\hline 2 & $11(34.38)$ & $2(15.38)$ & Reference & & & \\
\hline 3 & $16(50.00)$ & $7(53.85)$ & $2.39(0.50-11.52)$ & 0.277 & & \\
\hline 4 & $3(9.38)$ & $4(30.77)$ & $4.74(0.86-26.03)$ & 0.073 & & \\
\hline APACHE II score & $9.44(5.28)$ & $13.15(3.34)$ & $1.14(1.02-1.26)$ & 0.022 & $1.08(0.96-1.22)$ & 0.222 \\
\hline LODS score & $3.28(1.46)$ & $3.77(1.83)$ & $1.23(0.87-1.72)$ & 0.242 & & \\
\hline Charlson index & $8.84(0.95)$ & $9.08(1.38)$ & $1.33(0.74-2.40)$ & 0.339 & & \\
\hline \multicolumn{7}{|l|}{ Anesthesia } \\
\hline $\mathrm{RA}$ & $5(15.63)$ & $6(46.15)$ & $3.42(1.10-10.66)$ & 0.034 & $2.82(0.87-9.07)$ & 0.083 \\
\hline $\mathrm{GA}$ & $22(68.75)$ & $6(46.15)$ & Reference & & Reference & \\
\hline GARA & $5(15.63)$ & $1(7.69)$ & $0.80(0.10-6.66)$ & 0.838 & $1.79(0.19-17.36)$ & 0.615 \\
\hline Operation time & $92.75(46.50)$ & $108.62(46.19)$ & $1.01(1.00-1.02)$ & 0.351 & & \\
\hline The presence of blood transfusion & $11(34.38)$ & $6(46.15)$ & $1.27(0.43-3.80)$ & 0.663 & & \\
\hline Net fluid balance per hour $>200 \mathrm{ml}$ & $18(56.25)$ & $6(46.15)$ & $0.77(0.26-2.29)$ & 0.635 & & \\
\hline
\end{tabular}

Values are presented as mean (SD). HR: hazard ratio, Cl: confidence interval, BMI: body mass index, ECOG: Eastern Cooperative Oncology Group performance status, ASA PS: American Society of Anesthesiologists physical status, APACHE: Acute Physiology and Chronic Health Evaluation, LODS: Logistic Organ Dysfunction score, RA: regional anesthesia, GA: general anesthesia, GARA: combined general and regional anesthesia. 


\section{DISCUSSION}

The incidence of metastatic pathologic fracture has increased because of the longer survival of cancer patients [7]. Skeletal metastases are a common occurrence in up to $80 \%$ of cancer patients [7]. Bone is a common site of metastases, after liver and lungs [10]. Pathologic fractures occur in $8 \%$ to $30 \%$ of patients with bone metastases $[7,10,11]$. Once a fracture occurs, the terminally ill cancer patient is at an increased risk for a variety of complications that can hasten death [3]. The risk of death associated with a pathologic fracture is increased by about $20 \%$ in these patients [3]. Treatment of pathologic fractures is by surgical stabilization, if possible $[7,12]$. The goal of palliative surgery is to lengthen life span, restore stability, preserve ambulation, alleviate severe pain that is unresponsive even to narcotics, and ultimately to optimize the quality of life $[2,6,8,13]$. However, the absolute indication and timing for palliative surgery for pathologic fractures is controversial $[13,14]$.

Tumors arising from the lung, breast, prostate, colon, thyroid, and kidney as well as multiple myeloma are prone to spread to bone $[3,9]$. Our case series is similar with other reports, where the most frequent primary tumor is lung tumor [4]. Patients with metastatic lung cancer have the worst prognosis as it is a highly aggressive neoplasm $[5,13,15]$. Our relatively high incidence of liver and stomach cases might be the reflection of the high prevailing incidence of these cancers in Korea [16].

The femur is the most frequent affected site of fracture because of metastatic cancer. Other sites that are frequently affected by bone metastases include the vertebral column, ribs, pelvis, radius, and skull $[2,6,8,10]$. The short survival period after pathologic fracture of the long bones has been reported in other study [17]. However, our finding about mortality in the patients with femur fractures is observed to be insignificant.

Surgical treatment of pathologic fractures may be followed soon by death, contrary to expectations [2]. Surgery is not advised if a patient is too debilitated to withstand the surgery, or if the expected survival time is too short to recover sufficiently to benefit from the operation [8]. Palliative operations that are performed indiscreetly could be devastating for the patients [3]. Serious complication or unexpected early death would compound the unnecessary suffering including apprehen- sion for the operation and postoperative pain. Some patients with a limited life expectancy may undergo unnecessary palliative operations [8]. We hypothesized that these poor clinical results, with some immediate postoperative deaths in these very ill patients, suggest the patient of surgery can be selected inappropriately. If it is anticipated that patients will require intensive care facilities and experience significant postoperative complications in terms of their surgery-related condition, then palliative surgery is unjustified [13]. We modified these suggestions to apply to our hypothetical conditions.

There is little agreement on allowance of remaining lifespan on which time limit to base the decision of operation [17]. Patients with a life expectancy of less than six weeks rarely gain useful benefit from major surgery $[13,14]$. In present study, most of the reports recommended the remaining survival as 6 months for the palliative operation $[13,18]$.

Predicting life expectancy in terminal cancer is important for clinicians because a poor survival estimate can make a clinical decision about appropriate palliative treatment harder [19]. In general, lifespan is difficult to estimate accurately $[14,19]$. If there are the clinical condition (the common terminal pathway) that include precipitously decreased performance, anorexia-cachexia, dyspnea, dysphagia, and delirium, the signs should preclude the administration of general anesthesia $[7,14,19]$.

Several disease severity and organ dysfunction scoring systems including American Society of Anesthesiologists physical status classification [15], ECOG scale, which is the scoring system for performance status in terminal cancer patients [20], APACHE II score [21], LOD system score [22], and Charlson co-morbidity index [23,24], which could reflect numerous comorbid conditions, were presently applied to discern their predictable capability. We suggested the possibility of APACHE II scoring in making clinical decision of surgery for patients with pathologic fractures.

The underlying diseases in cancer patients include malnutrition, superimposed infection, chemotherapy-induced lung injury, ectopic hormone production and electrolyte imbalance including hyponatremia, or hypercalcemia as well as local effects of cancers and distant metastases [9,15,25]. The affected patients are mostly older, at an advanced stage, and have medically incurable diseases including rejected chemotherapy by their own will and recognition of the potential adverse effects of opioids in some narcotic-dependent patients 
[15]. It is essential that the general poor condition of the patient is addressed before surgery, if possible $[13,15]$. However, it is often impossible, as in performing breathing exercises to optimize pulmonary function and hyperalimentation to correct nutritional deficiencies [15]. In addition, multiple sites of bony metastases and the presence of visceral metastases are associated with a poor prognosis [7,9,12]. Additional organ involvements lower survival compared to patients whose disease remains clinically confined to the skeleton [9]. However, the mean postoperative survival for patients with metastases confined to the operated bone compared to patients with coexistence of osseous and nonosseous metatstases was not statistically significance according to the number of organs and other bones in our study due to unknown reason. Reportedly, patients with more co-morbidities, uncontrolled primaries, and widespread metastases experience heightened mortality [26].

Postoperative cell-mediated immunity suppression, the first-line defense mechanism against cancer, is associated with underlying illness, direct effect of anesthetics, pain, stress-related hormonal changes, hemorrhage and transfusions, ischemia-reperfusion, and factors including age and gender [27]. Therefore, we investigated to find out more about these effects on our patients.

Gottschalk et al. [27] suggest the hypothesis that surgical stress response increases the likelihood of cancer dissemination and metastasis during and after cancer surgery. Anesthetic method in cancer patient might potentially influence outcome including long-term survival [25]. Therefore the possible method for metastasis prevention by the anesthesiologist opioids, COX inhibitor, $\alpha_{2}$-adrenergic agonist, $\beta$-adrenergic blockade, regional anesthesia, suppression of blood transfusion, and perioperative hypothermia was suggested [27]. The type of anesthesia, especially regional anesthesia, may play a role in this process and could indirectly affect malignant cell development and attenuate surgery-induced increases in malignant proliferation [27]. The addition of regional anesthesia to general anesthesia also results in less overall use of volatile anesthetics and opioids, theoretically resulting in less immunosuppression [27]. Further studies are needed to establish the benefits of regional anesthesia in patients with pathologic fractures given in our result.

Cancer patients who receive blood transfusions during surgery may tend to do worse probably due to transfusion- related immunosuppression [27]. The present findings do indicate that this is unlikely. It may be that both anemia and blood transfusions are associated with harmful effects in cancer patients. Perhaps factors influencing the need for blood transfusion have a greater influence on prognosis than the receipt of blood itself [27]. The duration of anesthesia and net fluid balance also have not been associated with an increased risk for developing morbidity and mortality, both presently and previously study [27].

The intraoperative occurrence of difficult ventilation, intubation, and subsequent hypoxemia due to head and neck cancers, history of radiation exposure, pulmonary mass itself, or fat embolism, may be the possible events in these patients $[15,18,28]$. Pathologic fractures of the ribs also can impair ventilation $[9,15]$. Postoperative complications include pneumonia, respiratory failure, renal failure, disseminated intravascular coagulation, hepatic failure, cerebral infarct, adrenal crisis, vegetative state, and death $[15,18,28,29]$. Postoperatively, some patients may require mechanical ventilation or vasopressor therapy for shock [25].

The present study has several limitations. It was conducted at a single center with a limited sample size. The data of some palliative operations may be outdated. A few decades ago the survival following recognition of bone metastases was poorer than is at present [30]. Patient variation in preoperative history and antitumor therapy prior to surgery was marked and their preoperative status could not be analyzed in a meaningful way. Heterogeneities concerning the type and complexity of the operations may affect the comparison between the groups. The variety of devices used by the different surgeons does not allow the clear discernment of the effect of the surgical procedure on patient outcome [2]. Lack of surgeon's experience in palliative surgery may increase the risk of an undesirable outcome [28]. We excluded the effects of cell type, stage, and the patient's detailed health problems because these aspects go beyond the objective of the study. Because of these limitations, our findings must be recognized as preliminary.

In the absence of firm data, the argument for palliative surgery is whether to perform an operation for patients who will realize benefits, or avoid operation for inappropriate patients to eliminate the considerable risks of surgery. Our results provide another warning against reckless application of surgery in these patients. In the absence of reliable indicators of the 
patient's life expectancy, the value of these palliative operations cannot help but remain obscure. Anesthesiologists involved in both surgical operations, intensive care, and palliative pain therapy should play a leading role in preoperatively evaluating general status and participate in deciding the plan of palliative surgery within the context of a multidisciplinary team approach.

Palliative surgery for pathologic fracture could likely result in suitable outcome if the patient with high APACHE II score is paid more attention. Our result of lung tumor as main negative factor affecting postoperative survival suggests that a prudent anesthetic approach is essential in patients with lung carcinoma. We conclude that a patient's preoperative medical condition is the major determining factor for the postoperative outcome. Factors associated with anesthesia themselves do not have a statistically meaningful correlation with the prognosis of these patients. Clearly more time and resources are required to refine the safe anesthetic management in terminal cancer patients with pathologic fractures.

\section{REFERENCES}

1. Snyder BD, Cordio MA, Nazarian A, Kwak SD, Chang DJ, Entezari V, et al. Noninvasive prediction of fracture risk in patients with metastatic cancer to the spine. Clin Cancer Res 2009; 15: 7676-83.

2. Sarahrudi K, Greitbauer M, Platzer P, Hausmann JT, Heinz T, Vécsei V. Surgical treatment of metastatic fractures of the femur: a retrospective analysis of 142 patients. J Trauma 2009; 66: 115863.

3. Saad F, Lipton A, Cook R, Chen YM, Smith M, Coleman R. Pathologic fractures correlate with reduced survival in patients with malignant bone disease. Cancer 2007; 110: 1860-7.

4. Hirsh V. Skeletal disease contributes substantially to morbidity and mortality in patients with lung cancer. Clin Lung Cancer 2009; 10: 223-9.

5. Reich CD. Advances in the treatment of bone metastases. Clin J Oncol Nurs 2003; 7: 641-6.

6. Behr JT, Dobozi WR, Badrinath K. The treatment of pathologic and impending pathologic fractures of the proximal femur in the elderly. Clin Orthop Relat Res 1985; (198): 173-8.

7. Janjan N. Bone metastases: approaches to management. Semin Oncol 2001; 28(4 Suppl 11): 28-34.

8. Ward WG, Spang J, Howe D, Gordan S. Femoral recon nails for metastatic disease: indications, technique, and results. Am J Or- thop (Belle Mead NJ) 2000; 29(9 Suppl): 34-42.

9. Coleman RE. Skeletal complications of malignancy. Cancer 1997; 80(8 Suppl): 1588-94.

10. Narazaki DK, de Alverga Neto CC, Baptista AM, Caiero MT, de Camargo OP. Prognostic factors in pathologic fractures secondary to metastatic tumors. Clinics (Sao Paulo) 2006; 61: 313-20.

11. Higinbotham NL, Marcove RC. The management of pathological fractures. J Trauma 1965; 5: 792-8.

12. Coleman RE. Clinical features of metastatic bone disease and risk of skeletal morbidity. Clin Cancer Res 2006; 12: 6243s-9s.

13. British Orthopaedic Association. Metastatic bone disease: a guide to good practice. London, British Orthopaedic Oncology Society \& British Orthopaedic Association. 2000, pp 19-20.

14. Zickel RE, Mouradian WH. Intramedullary fixation of pathological fractures and lesions of the subtrochanteric region of the femur. J Bone Joint Surg Am 1976; 58: 1061-6.

15. Hines RL, Marshall KE. Stoelting's anesthesia and co-existing disease. 6th ed. Philadelphia, Saunders. 2012, p 493.

16. Park BM, Chung IH, Kang SY. Clinical analysis on the metastatic bone tumors. J Korean Orthop Assoc 1982; 17: 36-47.

17. Van der Linden YM, Dijkstra PD, Kroon HM, LokJJ, Noordijk EM, Leer JW, et al. Comparative analysis of risk factors for pathological fracture with femoral metastases. J Bone Joint Surg Br 2004; 86: $566-73$.

18. Tsukeoka T, Kochi T, Koide K, Tahara M, Koyama T, Kitou M, et al. [The risk of palliative operation for bone metastasis]. Masui 1997; 46: 1634-8. Japanese.

19. Cheng WH, Kao CY, Hung YS, Su PJ, Hsieh CH, Chen JS, et al. Validation of a palliative prognostic index to predict life expectancy for terminally ill cancer patients in a hospice consultation setting in Taiwan. Asian Pac J Cancer Prev 2012; 13: 2861-6.

20. Oken MM, Creech RH, Tormey DC, Horton J, Davis TE, McFadden ET, et al. Toxicity and response criteria of the Eastern Cooperative Oncology Group. Am J Clin Oncol 1982; 5: 649-55.

21. Rowan KM, Kerr JH, Major E, McPherson K, Short A, Vessey MP. Intensive Care Society's APACHE II study in Britain and Ireland-II: outcome comparisons of intensive care units after adjustment for case mix by the American APACHE II method. BMJ 1993; 307: 977-81.

22. Lemeshow S, Le Gall JR. Modeling the severity of illness of ICU patients. A systems update. JAMA 1994; 272: 1049-55.

23. Charlson ME, Pompei P, Ales KL, MacKenzie CR. A new method of classifying prognostic comorbidity in longitudinal studies: development and validation. J Chronic Dis 1987; 40: 373-83.

24. Monk TG, Saini V, Weldon BC, Sigl JC. Anesthetic management and one-year mortality after noncardiac surgery. Anesth Analg 2005; 100: 4-10. 
25. Benumof JL. Anesthesia and uncommon diseases. 4th ed. Philadelphia, W.B. Saunders Company. 1998, p 545.

26. Sharma H, Bhagat S, McCaul J, Macdonald D, Rana B, Naik M. Intramedullary nailing for pathological femoral fractures. J Orthop Surg (Hong Kong) 2007; 15: 291-4.

27. Gottschalk A, Sharma S, Ford J, Durieux ME, Tiouririne M. Review article: the role of the perioperative period in recurrence after cancer surgery. Anesth Analg 2010; 110: 1636-43.

28. Barwood SA, Wilson JL, Molnar RR, Choong PF. The incidence of acute cardiorespiratory and vascular dysfunction following intramedullary nail fixation of femoral metastasis. Acta Orthop Scand 2000; 71: 147-52.

29. Roumen RM, Lako SJ, Schoots FJ. Acute lung damage after bilateral insertion of femoral intramedullary interlocking nails for metastatic bone disease. Eur J Surg 1995; 161: 451-3.

30. White BL, Fisher WD, Laurin CA. Rate of mortality for elderly patients after fracture of the hip in the 1980's. J Bone Joint Surg Am 1987; 69: 1335-40. 